\title{
Multinucleated stromal giant cells in adolescent
}

\section{gynaecomastia}

\author{
A P Campbell
}

\begin{abstract}
Bizzare multinucleated stromal giant cells were observed in a case of adolescent gynaecomastia. Similar cells have been described in the female breast in both benign and malignant conditions where they are thought to originate either from reactive stromal cells or from the mononuclear phagocyte system, respectively. Immunohistochemistry and electron microscopy in this case support the idea that they originate from stromal fibroblasts. Their occurrence in gynaecomastia is further evidence that these changes in stromal cells may be due to hormonal influences.
\end{abstract}

Multinucleated giant cells have been described in the female breast in both benign and malignant conditions. ${ }^{12}$ These seem to be either (1) osteoclast-like giant cells, possibly originating from the mononuclear phagocyte system, which occur within an infiltrating carcinoma, ${ }^{3}$ or (2) "reactive" multinucleated stromal giant cells occurring independently, or in the absence, of tumour. ${ }^{1}$ Cells similar to the latter may occur in the lower female genital tract where electron microscopic examination has shown that they are fibroblastic in nature. ${ }^{4}$ Atypical, multinucleated, fibroblastic cells have also been reported in the bladder, prostate, urethra and nasal polyps. ${ }^{4}$ It is important to recognise these cells as they are a possible source of confusion with malignancy. The cause is unknown but it is thought that in some cases these changes may be due to hormonal influences. ${ }^{4}$

I have recently encountered a case of multinucleated stromal giant cells occurring in adolescent gynaecomastia. This case may shed further light on their nature and pathogenesis.

\section{Case report}

A 19 year old boy presented with a 12 month history of gynaecomastia. He was known to have neurofibromatosis but had no other medical history of note. All investigations, including human chorionic gonadotrophin concentrations and an abdominal ultrasound scan to exclude the presence of a neurofibroma pressing on an adrenal gland, were normal. A bilateral subcutaneous mastectomy was performed from which he made a good recovery.
Nuffield Department of Pathology and Bacteriology, Level 4, Academic Block, John Radclifie Hospital, Headington, Oxford OX3 9DU

A P Campbell

Correspondence to: Dr A P Campbell Accepted for publication 18 September 1991

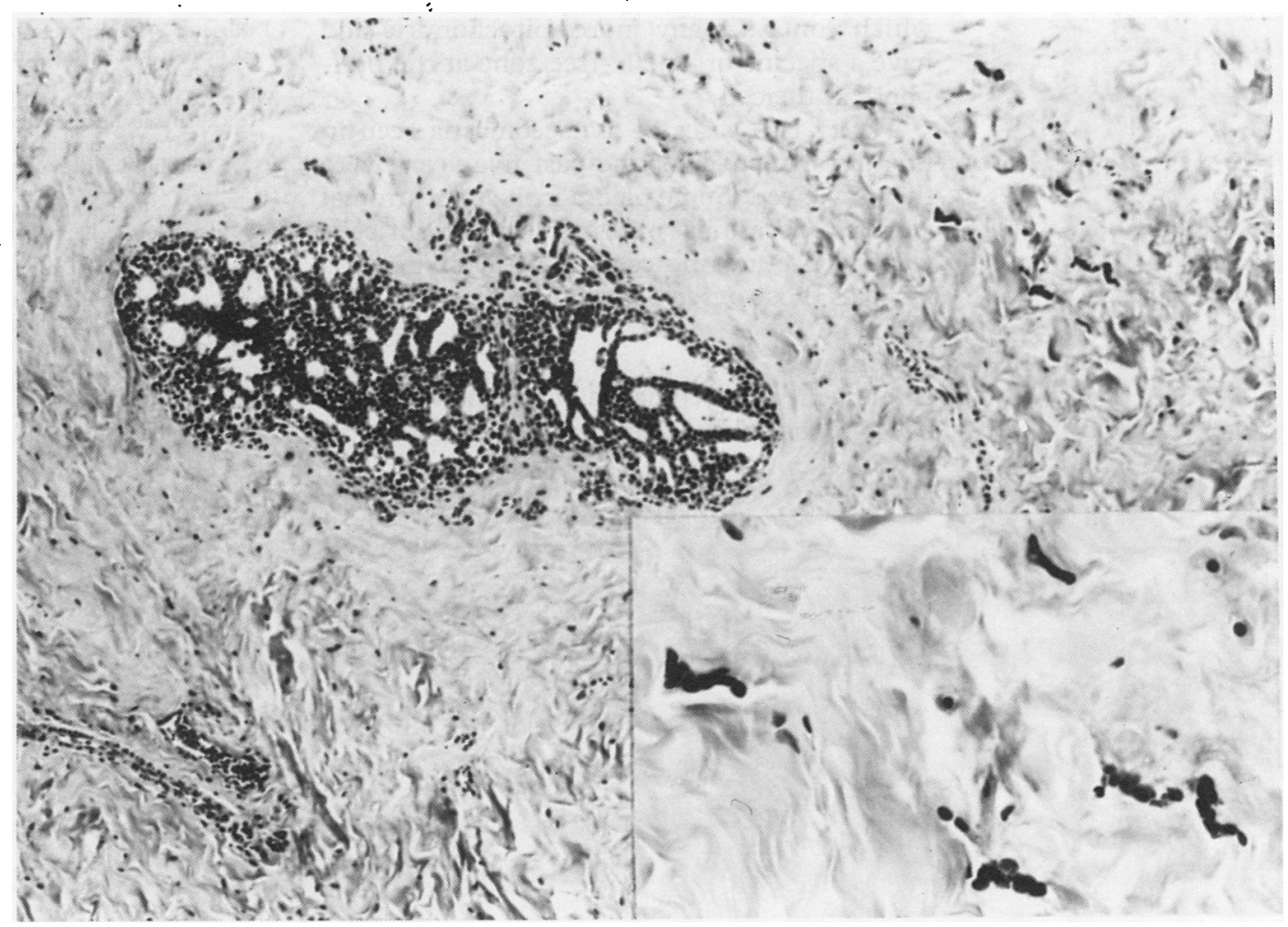

Figure 1 Low power view of gynaecomastia with atypical multinucleated giant cells lying in collagenous stroma (haematoxylin and eosin). High power inset. 


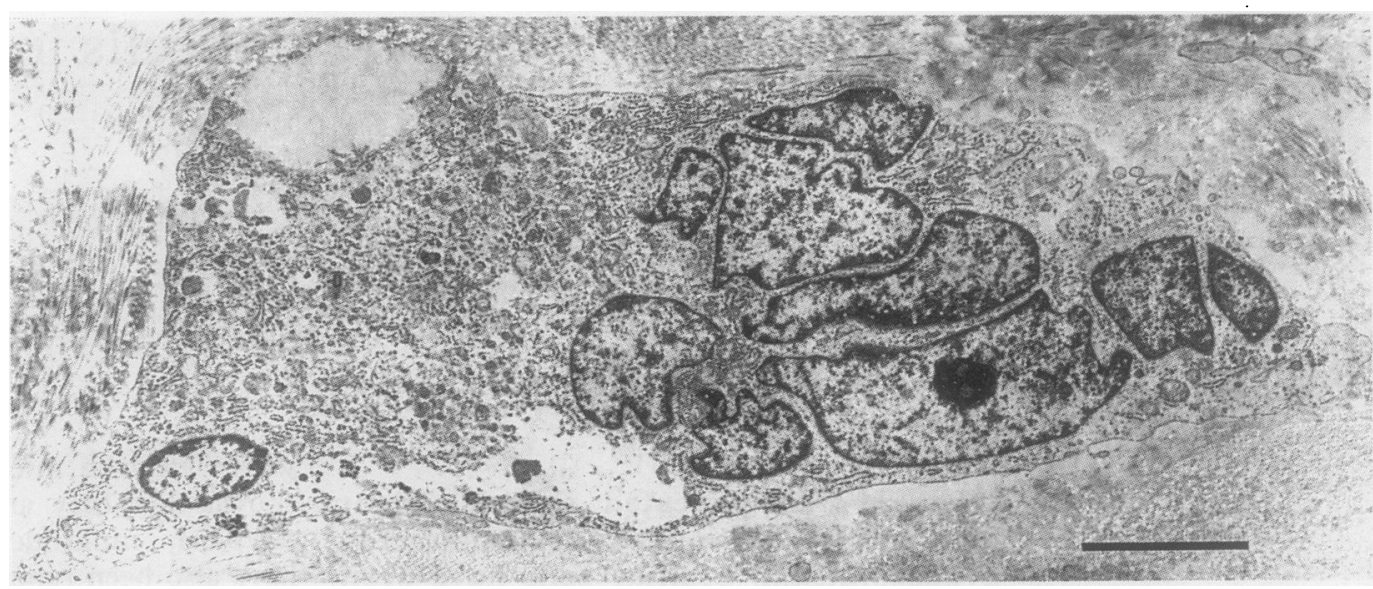

Figure 2 Electron micrograph of a multinucleated giant cell. The bar is $5 \mu m$.

\section{Pathological findings}

Routine histological examination showed changes of gynaecomastia with the additional finding of bizarre stromal cells, many of which were multinucleate, and scattered throughout both specimens (fig 1). Immunohistochemistry showed that the cells were positive for vimentin (V9) but negative for leucocyte common antigen (PD7/26), macrophage markers (KP1 and Mac 387), $\alpha-1$ antitrypsin, lysozyme, cytokeratins (LP34 and MNF116) and epithelial membrane antigen (E29). All these antibodies are commercially available from Dakopatts a/s.

Electron microscopic examination showed strands of rough endoplasmic reticulum and a few mitochondria in the cytoplasm of the multinucleated cells (fig 2). These features are similar to those seen in the adjacent fibroblasts. They differ significantly from the osteoclastlike giant cells seen in certain breast carcinomas which contain many more mitochondria and have a specific organelle-free zone at the periphery of the cell. ${ }^{2}$

Thirty two cases of gynaecomastia seen in this department over the past five years were then reviewed. Some pleomorphism of stromal cells and occasional multinucleated giant cells were seen but in no case were the changes as florid as those described above.

\section{Discussion}

Adolescent gynaecomastia is common and has been reported to occur in up to $65 \%$ of teenagers. ${ }^{5}$ Most resolve spontaneously and only a few cases require surgery. ${ }^{6}$

The cause is thought to be hormonal imbalance. Raised oestrogen concentrations, abnormal oestrogen: testosterone ratios, and a decrease in free testosterone concentrations have all been reported, albeit inconsistently. ${ }^{5}$

Hormonal factors are thought to play a part in the pathogenesis of multinucleated stromal giant cells occurring at other sites. ${ }^{4}$ The finding of these cells in adolescent gynaecomastia which is also hormonally influenced provides further evidence that this might be the case.

The immunohistochemical and electron microscopic findings given here support an origin from stromal fibroblasts.

I thank Mr AR Heryet and Dr DP Ferguson for their exper technical assistance and Mr N Dudley for allowing me to repor this case.

1 Rosen PP. Multinucleated mammary stromal giant cells: A benign lesion that simulates invasive carcinoma. Cancer 1979;44:1305-8.

2 Page DL, Anderson TJ, Connolly JL, Schnitt SJ. Miscellaneous features of carcinoma. In: Page DL, Anderson TJ, eds. Diagnostic histopathology of the breast. Edinburgh: Churchill Livingstone, 1987:269-99.

3 Athanasou NA, Wells CA, Quinn J, Ferguson DP, Heryet A, $M c G e e$ JO'D. The origin and nature of stromal osteoclastlike giant cells in breast carcinoma: implications for tumour osteolysis and macrophage biology. $\mathrm{Br} J$ Cancer 1989;59:491-8.

4 Abdul-Karim FW, Cohen RE. Atypical stromal cells of the lower female genital tract. Histopathology 1990;17:249-53. lower female genital tract. Histopathology 1990;17:249-53.
Biro FM, Lucky AW, Huster GA, Morrison JA. Hormonal studies and physical maturation in adolescent gynaecomastia. J Paediatr 1990;116:450-5.

6 Carlson HE. Current concepts: Gynecomastia. $N$ Engl J Med 1980;303:795-9. 